\title{
Therapeutic risk-taking: a justifiable choice
}

\author{
Anne Felton, Nicola Wright \& Gemma Stacey
}

\begin{abstract}
SUMMARY
Taking risks is a fundamental part of the human experience that supports personal growth. Therapeutic risk-taking enables patients to make decisions about their level of safety and to pursue goals. Promoting therapeutic risk-taking can be complex. Professionals can experience tension striving for a balance between the interests of the individual and societal pressures to control risk. This article examines therapeutic risk-taking, recognising the challenges to supporting it in practice and debating how they may be overcome.
\end{abstract}

\section{LEARNING OBJECTIVES}

- Be able to explain what therapeutic risk-taking is and discuss its application to psychiatric practice

- Understand the factors that challenge and enable therapeutic risk-taking in psychiatric practice

- Describe the association between therapeutic risk-taking and recovery

\section{DECLARATION OF INTEREST}

None

Therapeutic (or positive) risk-taking is increasingly recognised as a significant way of supporting patients $^{\text {a }}$ towards recovery (Morgan 2007). However, it remains elusive as a core component of mental healthcare. This article explores debates surrounding therapeutic risk-taking, presenting an argument that it is a justifiable choice essential to redress the high prevalence of risk aversion in mental health practice.

Therapeutic risk-taking (Box 1) involves empowering patients to make decisions regarding their own safety and to take risks to enable personal development. Enshrined in the Department of Health's Essential Shared Capabilities Framework as a core value of contemporary mental healthcare, it involves patients making choices and having control (Morgan 2000; Department of Health 2004). Therapeutic risk-taking is underpinned by recognition that risk is not solely defined in terms of harm, hazards and danger. Risk can also create possibility, opportunity and achievement (Morgan 2004). Viewed through this lens, risk-taking is a fundamental part of psychological growth and change for all, not only in terms of the gains that may be derived from taking a risk, but also from the reflective learning that can develop if these gains are not achieved.

The language of risk can, however, pose a challenge to this perspective. As a social construct the term risk is understood as synonymous with harm and danger, and it operates in a society preoccupied with reducing the likelihood that harm will occur (Beck 1992). Creating space to recognise risk is difficult when this is the normative view. Understanding risk as symbolising harm means that risk-taking can be perceived as outside the norm. Making life choices can therefore can become redefined as a risk that threatens both empowerment and the recognition of people with mental health problems as autonomous individuals exercising rights. For example, deciding to reduce or stop medication is a decision about treatment. Applying for a university course or job is a choice about personal development and lifestyle, which for any individual carries the potential of successful or unsuccessful outcomes. Defining these decisions as a therapeutic risk may inadvertently serve to perpetuate the view that people with mental health problems pose a risk - are 'risky'. Some shift in language from 'risk' to 'safety' is beginning to be evident in the development of a discourse about 'person-centred safety plans' (Boardman 2014), and this may help to normalise risk-taking. The phrase therapeutic risk will be adopted in this article as, alongside the expression positive risktaking, this is currently a term in common usage.

\section{BOX 1 Principles of therapeutic risk-taking}

- Decision-making is joint between professionals and patients

- Information is shared clearly to promote informed choice

- Patients' capabilities and strengths are drawn on

- The outcomes of a decision are managed by effective assessment and collaborative planning

- It is accepted that risk-taking may result in positive achievements, not just negative events
Anne Felton is an Associate Professor in Mental Health at the School of Health Sciences at the University of Nottingham. She has worked as a nurse in in-patient and community rehabilitation services. Her $\mathrm{PhD}$ thesis examined the tensions created for professionals dually responsible for risk management alongside promoting recovery. She has conducted qualitative research in risk and mental health practice, social inclusion and service user involvement in healthcare professional education. Nicola Wright is an Assistant Professor in Mental Health in the School of Health Sciences, University of Nottingham. As a mental health nurse she has worked in both acute in-patient and assertive community treatment teams. Her research interests have focused on the use of qualitative methods to evaluate mental health service provision and knowledge-sharing gaps at care transition points. She has undertaken projects on concepts of recovery and self-management for young people who self-harm. Gemma Stacey is an Associate Professor in the School of Health Sciences, University of Nottingham. Her research interests include the educational factors that influence the development, maintenance and expression of personcentred values. She is the leader of the Critical Values Based Practice Network, which conducts research in this area, along with an explicit focus on the perception and influence of power and hierarchy in professional groups. Correspondence Dr Anne Felton, Institute of Mental Health Building, University of Nottingham Innovation Park, Triumph Road, Nottingham NG7 2TU, UK. Email: anne.felton@nottingham.ac.uk

\section{Copyright and usage}

(C) The Royal College of Psychiatrists 2017.

a. The language used to describe people who use mental health services is contested, with the preferred term often in a state of flux. The term 'patient' has been used throughout this article. 
However, this limitation highlights a need to be attentive to the language that we use and the ideas it represents.

\section{The patient's place in current risk practice}

The assessment and management of risks associated with patients is a fundamental part of psychiatric practice. Risk has an important influence on decision-making, including when people move between services (Bowers 2005). However, conceptualisations of risk are dominated by understanding patients as a danger to either themselves or others. This perpetuates a view that risk is something to be avoided and minimised (Hawley 2006; Ryan 2010). Mental health professionals are therefore positioned as responsible for identifying, quantifying and containing risk. This aspect of the professional role has been seen to be a mechanism of control, potentially threatening the therapeutic focus and acting as a barrier to recovery-oriented relationships with patients (Szmukler 2013; Royal College of Psychiatrists 2016). Crucially, it undermines the visibility of people with mental health problems in the decision-making process. Involvement of patients in discussions and plans relating to risk remains rare, with many individuals being unaware that they have been subject to a risk assessment (Langan 2004; Dixon 2012; Coffey 2016).

The capacity for therapeutic risk-taking is therefore limited as patients lack the opportunity to make decisions about their safety. Compared with the volume of literature on risk in mental healthcare, there is a dearth of studies that examine patients' views. However, there is some evidence to suggest that patients identify a wider range of risks than professionals, particularly risks associated with treatment, such as medication side-effects (Langan 2004; Dixon 2012; Sykes 2015). Without the involvement of patients, the focus is inevitably on risk to self and others, as alternative sources of harm remain less visible and excluded from assessments. The dominance of risk of harm to self or others also serves to more readily justify interventions that may restrict enjoyable activities or remove choice from patients, while intensive riskmonitoring can perpetuate stigma and isolation (Coffey 2012). Clarke $\&$ Mantle (2016) describe these restrictions as 'silent harms', as their impact is much less apparent to professionals.

These problems with current risk practice are confounded by the extensive debate regarding the validity of risk assessment tools, the evidence base for risk assessment practices and recognition that many organisations develop their own unvalidated risk assessment processes for local needs (Morgan 2007; Higgins 2016a; Royal College of Psychiatrists 2016). Such debate helps to create an arena for promoting different ways of understanding risk and enabling therapeutic risk-taking.

\section{Balancing potential short-term harm against long-term benefits}

This critical perspective does not deny that there is a genuine potential for harm to occur. However, it should be recognised that extreme harm relates to a minority of people in contact with mental health services (Ryan 2010; Appleby 2013). It is important, therefore, that risk management strategies recognise the relative rarity of these incidents (Ryan 2010; Boardman 2014). Developing a collaborative and contextual understanding of both the potential harms and gains of a decision means that therapeutic risk-taking is both possible and desirable within mental health practice. This perspective also aligns with best practice guidelines, which recognise that the elimination of risk is impossible and that preventing people from taking risks can inhibit personal recovery (Department of Health 2007; Morgan 2007; Boardman 2014). Therapeutic risk-taking can help patients to make informed decisions supported by collaborative person-centred care plans, which provide individualised support. Through a more personalised approach to risk, it is possible to balance the potential for harm to occur in the short term against the possibility of achieving gains over a longer timescale. Examples of this within mental healthcare include reducing medication and a harm minimisation approach to self-harm.

\section{Shifting perceptions of patients and risk}

Being able to engage in mental health practice that promotes therapeutic risk-taking and supports individuals in taking risks necessitates a shift in thinking about the nature of mental illness, the role of the practitioner and the individual patient. Within this context, people with mental health problems can no longer be seen as what Foucault (1977) termed docile bodies, but should instead be perceived as experts in their own lives. Foucault (1977) argued that docile bodies are people that not only do what is expected of them, but also do it in a way deemed to be correct. They are produced by observation (or the potential to be observed) in combination with a concern for normative judgement (actions ranked on a scale in comparison with everyone else). Many risk assessment tools, for example, depend on this combination. Foucault (1977) termed this process 'examination' and, with its associated documentation, it seeks to 
make the individual visible within a network of writing. For example, psychiatric patients often have large volumes of medical records that are maintained and scrutinised by the practitioners working with them.

Although Foucault's (1977) analysis was theoretical, it resonates with many patient narratives regarding the care and treatment they have received and continue to receive from mental health services. Risk assessment tools and protocols often involve ranking an individual's behaviour and recording this process to ensure that information is passed on, therefore increasing a person's visibility within the healthcare system. Throughout this process, the practitioner's view is dominant and the patient is a case to be studied and an object of care (Gutting 2005). Perhaps this is not surprising, given the presence of the mental health legislation that can be enacted should someone present as a risk to self or others. However, there is a question to be answered as to whether ensuring compliance (docility) and judging individuals against the norm promotes safety and recovery in the long term.

\section{The concept of recovery}

Throughout history, definitions of mental health and mental illness have been dominated by the professional and academic discourse. However, the growth of the consumer/survivor movement has led to increasing interest in the concept of recovery (Davidson 2010). Recovery broadly refers to the real-life experience of people as they accept and overcome the challenge of being socially disabled by their mental ill health and 'recover' a new sense of self (Deegan 1988).

Understanding and recognising the importance of an individual's experience of mental distress from their own perspective has gained increasing prominence (Shepherd 2008). At its core the consumer/survivor movement is based on ideas relating to self-help, empowerment and advocacy (Shepherd 2008) and it provides a challenge to the traditional notion of professional power and dominance (Frese 1997). Shepherd et al (2008) suggest that these are not new concepts and that they can be traced back to the American civil rights movement of the 1960s and 1970s. However, Frese \& Davis (1997) argue that the modern consumer/survivor movement developed without any knowledge of its historical roots. In England, it dates back to the establishment of the Alleged Lunatics' Friend Society (Hervey 1986) and in the USA to the period immediately following the American Civil War (Frese 1997). Promoting the rights of people with mental health problems to take risks has been a feature of the service user movement, advocated as a means of empowerment and an expression of citizenship (Kelmshall 2009).

In reference to recovery, Anthony (1993: p. 527) argues that:

'recovery is described as a deeply personal, unique process of changing one's attitudes, values, feelings, goals, skills and/or roles. It is a way of living a satisfying, hopeful and contributing life even with the limitations caused by illness. Recovery involves the development of new meaning and purpose in one's life as one grows beyond the catastrophic effects of mental illness'.

Thus, the recovery concept provides an alternative view to that which sees mental health problems as having an inevitable downward and deteriorating course. This is important in relation to notions of risk because if, as Harding et al (1987) emphasise, people with mental health problems do recover, can have meaningful lives and can be successfully employed, then cocooning them in a risk-free environment does not help them to achieve these things. If instead the principles of recovery are incorporated into clinical practice and lived experience is valued, therapeutic risktaking becomes a possibility. If as professionals we work with those with mental health problems and value their unique experiences we can enter into a power-sharing relationship, where risk and recovery are part of an ongoing dialogue. This will enable individuals to make choices, pursue selfdetermination, achieve their potential and move beyond the limitations imposed by severe mental health problems (Davidson 2006).

\section{Professional dilemmas in therapeutic risk-taking}

The opportunity to make decisions that involve the potential for gains or losses to be experienced recognises patients as autonomous individuals with the right to make choices about their own lives. Supporting this in practice creates tensions for professionals. In the face of legal, organisational and professional constraints, treading a path between safety, restriction and opportunity is complex. Mental health professionals commonly report experiencing dilemmas when trying to facilitate positive risk-taking. These pressures include weighing up the individual's rights, professional duties of care, public safety and awareness of possible consequences for the practitioner themselves (Robertson 2011; Nolan 2012). If significant harm does occur, apparent failures in risk assessment are more visible. Hindsight can skew the interpretation of events: when the outcome is known it is easier to see what the 'right' decision would have been. This 
retrospective judging places a greater burden on professionals who have to gauge an acceptable level of risk and make the 'right' decision in the first place, without the benefit of hindsight (Kemshall 2009). Yet the very definition of risk is that the outcomes are unknown. Professionals' concerns may be exacerbated by apparent tensions at a policy level, which reflect a consistent focus on public safety and containing risk, alongside a growth in the emphasis on recovery. Psychiatrists can be in a difficult position, facing criticism for propagating practice that is driven by the social control of a marginalised group alongside condemnation for failing to act and to carry out their duty of care (Morgan 2013). The balance between enabling choice and enacting control can be particularly difficult to maintain in the context of mental health legislation such as the Mental Health Act 1983 (as amended in 2007). Opportunities for choice and an individual's capability to manage choices at a particular time may be limited.

In light of such constraints, restriction (for example, community treatment orders, locked doors on in-patient wards, limited leave) can become the most easily justifiable option and the costs to patients of such interventions can be underestimated. False positives arising from risk assessments, particularly for those identified as high risk, can result in unnecessary containment, restrictive practices and additional medication, all of which raise moral and ethical concerns (Ryan 2010; Szmukler 2013). The nature of current risk assessment is a factor in denying people the opportunity to reach decisions, take risks and make mistakes. Protecting people who may already have damaged self-esteem from the impact of failing or being let down can further deter practitioners from supporting therapeutic risks. Yet risktaking in its broadest sense involves exercising

BOX 2 Therapeutic risk-taking and recovery

Therapeutic risk-taking promotes recovery by:

- encouraging people to pursue ambitions and goals

- facilitating shared decision-making

- counterbalancing the focus on harmful actions with the recognition of people's capabilities

- supporting autonomy and recognising individuals' agency

- allowing people to take control in their own lives

- recognising people's rights to take a risk and make mistakes

- encouraging self-management and self-determination agency and building self-confidence, processes that can be central to recovery and developing resilience (Box 2) (Felton 2015a). Deegan (1996: p. 97) suggests that, if they are to support recovery, professionals 'must embrace the concept of the dignity of risk and the right to failure'.

\section{Principlism in ethical decision-making}

Principlism, an approach that underpins ethical decision-making in healthcare, can confound the dilemmas experienced by professionals in relation to risk management and risk-taking. Practitioners may seek to justify decision-making based on promoting choice (autonomy) while also respecting professional duties to protect patients from harm (non-maleficence) and to promote good (beneficence) (Beauchamp 2000). Paternalism in mental healthcare is often justified on the premise of the best interests of the individual. Experiencing mental health problems can result in diminished capacity and difficulty exercising choices. When considered in this way, paternalistic practices that limit autonomy are justified if they are beneficent or non-maleficent.

If a person at risk is considered unable to make decisions because they have impaired competence (capacity), interventions against the person's will are not considered ethically disrespectful (Childress 1982). However, the notion of best interests is difficult, and in some instances the interpretation of paternalism can become muddled with the protection of others (Szmukler 2001). In this situation, the focus becomes on what the patient (or others) needs, as opposed to what that individual might prefer in an informed (competent) moment. A diagnosis of mental illness alone does not exclude someone from making an autonomous decision (Beauchamp 1984), a fact that leads to some criticism that principlism prioritises rational, universal and detached ethical reasoning (Roberts 2004). Therapeutic risk-taking often represents a situation in which one principle will conflict with another. If an autonomous decision is respected, it could be argued that this will conflict with the principle of beneficence. Likewise if a person's wishes are ignored, on the basis of preventing harm and promoting good, this would be in conflict with the principle of autonomy.

Such tensions underpin the need to provide practitioners with effective guidance and support to enable careful negotiation and a balance to be sought. However, in practice therapeutic risk-taking may be inhibited by organisational, professional and social constraints. In the next section, we examine these challenges and consider how some of these difficulties may be addressed to support patients towards recovery. 


\section{Developing therapeutic risk-taking in practice}

\section{Barriers to risk-taking}

Mental health professionals consistently identify organisational policies as undermining therapeutic risk-taking, through a lack of either clear guidance or organisational commitment (Robertson 2011; Boardman 2014). However, both are recognised as facilitating risk-taking practices that are safe and enable professionals to have the confidence to support patients in taking risks to achieve their goals. Organisations should have an interest in ensuring effective systems of risk assessment and management. In his analysis of the 'risk management of everything', Power states that such systems characterise a successful organisation, as they perpetuate a 'myth of control' over uncertainty and instil public confidence (Power 2004: p. 31). He advocates a new approach to risk for organisations, which involves recognising that risk is about imagining possibilities rather than predicting outcomes. Some shifts may have been made towards promoting this perspective, with influential bodies such as the Royal College of Psychiatrists (2016) recognising that the prediction of risk is problematic.

Organisational processes that are committed to supporting rather than blaming professionals and to facilitating learning in the context of adverse events are essential (Power 2004; Shepherd 2010). These are important features of developing a culture that is able to tolerate uncertainty, that values the patient's role in decision-making and that shares responsibility with the patient (Boardman 2014). Healthcare organisations also have the opportunity to commit to a different approach by extending the involvement of patients in local policy development on risk. Further embedding training in collaborative risk assessment and safety planning for professionals at an undergraduate and postgraduate level could continue to exert a positive influence on organisational practices (Higgins 2016b; Royal College of Psychiatrists 2016).

The risks of harm to self and others dominate risk assessment practice in psychiatry (Ryan 2010). One of the challenges that this poses to enabling therapeutic risk-taking is that risk becomes situated within the individual patient. Such embodiment of danger makes it difficult to move away from the perception that people with mental health problems are inherently risky (Felton 2015b; Clarke 2016). In fact, extensive evidence shows that they are more likely to experience extrinsic harm, for example as victims of domestic violence, violent crime and physical morbidity (Maniglio 2009; Pettitt 2013), than cause harm. When promoting autonomous decision-making and facilitating choices, people with mental illness should not be considered solely in terms of the dangers they present: recognising the full range of threats to their safety, alongside their strengths, successes and protective factors, can overturn their perceived identity as creators of risk. Refocusing risk in this manner creates further potential that the iatrogenic harms that result from restrictions may be incorporated into risk management. This would therefore facilitate a more balanced approach (Sykes 2015).

Alongside these barriers, there are a number of practices that support therapeutic risk-taking and enable it to be a reality in mental healthcare.

\section{Relational decision-making and risk}

Individualised knowledge of patients' subjective experiences promotes a contextual and detailed understanding of risk and safety (Felton 2015b). Connecting with the person's narrative enables a broad interpretation of threats and opportunities, and involving the individual in decision-making promotes therapeutic risk-taking. Additionally, this approach may create more accurate assessment as the quality and detail of information are enhanced. Assessing risk therefore becomes reconnected with the clinical examination, which is complemented rather than driven by documentation (Morgan 2013).

A therapeutic relationship with patients in which professionals clearly understand each individual's capabilities and draw these into decision-making both enables risk-taking and helps professionals to find a balance between safety and opportunity. In a study exploring risk-taking and recovery (Young 2015) it was suggested that patients valued practitioners who used person-centred knowledge to encourage them to challenge themselves. Open discussion recognises patients' own expertise and, through the development of advanced statements and plans, provides opportunity to plan for times when they may be more likely to be exposed to or cause harm (Gosling 2010).

Capturing different viewpoints, including those of family and significant others, is important to gain a contextual understanding of risk. Family perspectives on risk and safety are particularly marginalised, leaving carers feeling unheard (Gosling 2010). Professionals must negotiate these different viewpoints and draw on them in reaching their own conclusions and helping patients to make decisions. They will need to find ways of having a conversation about risk using language understood by all the stakeholders (Higgins 2016b). 
Principlism, which we mentioned above, has been recognised as a limited framework for promoting therapeutic risk-taking. Another approach can be found in 'ethics of care' theory, which draws on relational aspects of decision-making and calls for a greater focus on the patient's goals (Gilligan 1982). This approach requires a consideration of how a person feels and will introduce perspectives into the professional's ethical reasoning that may have been ignored using other frameworks. In seeking to negotiate different perspectives on risk and promote self-determination, professionals may benefit from drawing on these alternatives.

The collective expertise of professionals, patients and carers can be an important foundation for therapeutic risk-taking. Clinical judgements are vital when understanding risk (Morgan 2013; Higgins 2016a) and the opportunity to exercise autonomous decision-making facilitates recovery (Deegan 1988). Underpinned by collaborative planning and clear documentation, therapeutic risk-taking that promotes personal development while supporting safety is possible. This also reflects that therapeutic risk-taking is not a reason to do nothing or ignore sources of harm in the name of autonomy.

\section{Therapeutic risk-taking and the Mental Health Act}

For patients being cared for under the provisions of the Mental Health Act, small choices can have a significant impact; teams can seek ways to optimise choice within restrictions (Roberts 2008). This might include finding creative ways of sharing information with patients and advanced planning to enable them to communicate when ill choices that they made when well, including how to keep safe and when to take risk (Roberts 2008; Gosling 2010). Further research is needed to fully examine the development of risk-taking when patients are detained or subject to compulsory treatment in other ways, such as by community treatment orders.

\section{Supporting the professionals}

Creating a safe place for professionals to hold uncertainty is an important supportive component of risk-taking. Enabling therapeutic risk-taking is consistently recognised as a multidisciplinary rather than unidisciplinary process (Boardman 2014; Royal College of Psychiatrists 2016). Regular, inclusive and open discussion can promote shared responsibility, flexibility and creative decisionmaking. Clinical supervision and, increasingly, 'open dialogue' (Razzaque 2016) are recognised as examples of spaces where uncertainty can be safely held. Such spaces form part of Power's (2004) new politics of uncertainty for organisations in which these spaces nurture institutions' trust in professional judgements, enhancing less restrictive approaches to risk management.

Organisational polices and professional guidelines with an emphasis on protection, public safety and duties of care have been presented as undermining therapeutic risk-taking and more easily justifying restrictions. However, guidelines articulate a role for mental health professionals to support therapeutic risk-taking, enabling people to exercise choices and rights, striking a balance between this and a duty of care (Morgan 2007; Royal College of Psychiatrists 2014). Guidance from the Royal College of Psychiatrists (2016), Department of Health (2007) and Implementing Recovery through Organisational Change (ImROC) (Boardman 2014) promotes therapeutic risk-taking and recognises that some of the current problems with risk assessment and management undermine autonomy and restrict opportunities for recovery. Recognising these values within policy and professional guidelines provides a framework to help justify therapeutic risk-taking.

\section{Conclusions}

Therapeutic risk-taking facilitates the empowerment of patients as it enables them to make decisions regarding their own safety and to take risks to promote personal development and recovery. Therapeutic risk-taking is about exercising rights to make choices that can also involve making mistakes. Developing therapeutic risk-taking in a professional, organisational and social context that promotes risk aversion is clearly complex. It is an area where dilemmas for professionals are inevitable and there is a need to continue to examine their practice. However, by engaging in dialogue with patients and carers about safety and opportunity, working collaboratively as a multidisciplinary team and recognising professional responsibilities to strive for a balance, therapeutic risk-taking becomes a justifiable choice.

\section{References}

Anthony WA (1993) Recovery from mental illness: the guiding vision of the mental health service system in the 1990s. Psychosocial Rehabilitation Journal, 16: 521-8.

Appleby L, Kapur N, Shaw J, et al (2013) The National Confidential Inquiry into Suicide and Homicide by People with Mental IIIness. University of Manchester.

Beauchamp TL, McCullough L (1984) Medical Ethics. Prentice Hall.

Beauchamp TL (2000) The philosophical basis of psychiatric ethics. In Psychiatric Ethics (3rd edn) (eds S Bloch, P Chodoff, SA Green): 24-48. Oxford University Press.

Beck U (1992) Risk Society: Towards a New Modernity. Sage. 
Boardman G, Roberts G (2014) Risk, Safety and Recovery: A Briefing. Centre for Mental Health and Mental Health Network, NHS Confederation.

Bowers L, Simpson A, Alexander J, et al (2005) The nature and purpose of acute psychiatric wards: the Tompkins Acute Ward Study. Journal of Mental Health, 14: 625-35.

Childress JF (1982) Who Should Decide? Paternalism in Health Care. Oxford University Press.

Clarke C, Mantle R (2016) Using risk management to promote personcentred dementia care. Nursing Standard, 30(28): 41-6.

Coffey M (2012) A risk worth taking? Value differences and alternative risk constructions in accounts given by patients and their community workers following conditional discharge from forensic mental health services. Health, Risk \& Society, 14: 465-82.

Coffey M, Cohen R, Faulkner A, et al (2016) Ordinary Risks and Accepted Fictions: How Contrasting and Competing Priorities Work In Risk Assessment and Mental Health Care Planning. Health Expectations.

Davidson L, O'Connell M, Tondora J, et al (2006) The top ten concerns about recovery encountered in mental health system transformation. Psychiatric Services, 57: 650-5.

Davidson L, Rakfeldt J, Strauss J (2010) The Roots of the Recovery Movement in Psychiatry: Lessons Learned. Wiley-Blackwell.

Deegan P (1988) Recovery the lived experience of rehabilitation. Psychosocial Rehabilitation Journal 11: 11-9.

Deegan P (1996) Recovery as a journey of the heart. Psychiatric Rehabilitation Journal, 19: 91-7.

Department of Health (2004) The Ten Essential Shared Capabilities: A Framework for the Whole of the Mental Health Workforce. Department of Health.

Department of Health (2007) Best Practice in Managing Risk: Principles and Evidence for Best Practice in the Assessment and Management of Risk to Self and Others in Mental Health Services. Department of Health.

Dixon J (2012) Mentally disordered offenders' views of 'their' risk assessment and management plans. Health, Risk and Society, 14: $7-8$.

Felton A (2015a) Therapeutic risk-taking: what is it? Rivista Sperimentale di Freniatria, 3: 89-104

Felton A (2015b) 'Psychiatry is a Risk Business': The Construction of Mental Health Service Users as Risk Objects. A Multiple Case Study Inquiry. PhD thesis, University of Nottingham.

Foucault M (1977) Discipline and Punish: The Birth of the Prison. Trans from the original French (1975) by A Sheridan. Penguin Books.

Frese FJ, Davis WW (1997) The consumer-survivor movement, recovery and consumer professionals. Professional Psychology: Research and Practice, 28: 243-5.

Gilligan C (1982) In a Different Voice: Psychological Theory and Women's Development. Harvard University Press.

Gosling J (2010) The ethos of involvement as the route to recovery. In Mental Health Service User Involvement and Recovery (ed J Weinstein): 3-44. Jessica Kingsley.

Gutting G (2005) Foucault: A Very Short Introduction. Oxford University Press.

Harding CM, Brooks GW, Ashikaga T, et al (1987) The Vermont longitudinal study of persons with severe mental illness, 1: Methodology, study sample and overall status 32 years later. American Journal of Psychiatry, 144: 718-26.

Hawley C, Littlechild B, Sivakumaran T, et al (2006) Structure and content of risk assessment proformas in mental health care. Journal of Mental Health, 15: 437-48.

Hervey N (1986) Advocacy or folly: the Alleged Lunatics' Friend Society, 1845-63. Medical History, 30: 245-75.
Higgins A, Doyle L, Morrissey J, et al (2016a) Documentary analysis of risk-assessment and safety-planning policies and tools in a mental health context. International Journal of Mental Health Nursing, 25: 385-95

Higgins A, Doyle L, Downes C, et al (2016b) There is more to risk and safety planning than dramatic risks: mental health nurses' risk assessment and safety-management practice. International Journal of Mental Health Nursing, 25: 159-70.

Kemshall H (2009) Mental health, mental disorder, risk and public protection. In Mental Health Still Matters (eds J Reynolds, R Muston, T Heller, et al): 147-59. Palgrave Macmillan.

Langan J, Lindow V (2004) Living with Risk: Mental Health Service User Involvement in Risk Assessment and Management. Policy Press.

Maniglio R (2009) Severe mental illness and criminal victimization: a systematic review. Acta Psychiatrica Scandinavica, 119: 180-91.

Morgan S (2000) Clinical Risk Management: A Clinical Tool and Practitioner Manual. Sainsbury Centre for Mental Health.

Morgan S (2004) Positive risk-taking: an idea whose time has come. Health Care Risk Report, 10(10): 18-9.

Morgan JF (2007) 'Giving up the Culture of Blame': Risk Assessment and Risk Management in Psychiatric Practice (Briefing Document for the Royal College of Psychiatrists). Royal College of Psychiatrists.

Morgan JF (2013) Does the emphasis on risk in psychiatry serve the interests of patients or the public? Yes. BMJ, 346: f902.

Nolan D, Quinn N (2012) The context of risk management in mental health social work. Practice, 24: 175-88.

Pettitt B, Greenhead S, Khalifeh H, et al (2013) At Risk, Yet Dismissed: The Criminal Victimisation of People with Mental Health Problems. MIND

Power M (2004) The Risk Management of Everything: Rethinking the Politics of Uncertainty. Demos.

Razzaque R, Stockmann T (2016) An introduction to peer-supported open dialogue in mental healthcare. BJPsych Advances, 22: 348-56.

Roberts M (2004) Psychiatric ethics; a critical introduction for mental health nurses. Journal of Psychiatric and Mental Health Nursing, 11: 583-8.

Roberts G, Dorkins E, Wooldridge J, et al (2008) Detained - what's my choice? Part 1: Discussion. Advances in Psychiatric Treatment, 14: $172-80$

Robertson J, Collinson C (2011) Positive risk-taking: whose risk is it? Health, Risk and Society, 13: 147-64.

Royal College of Psychiatrists (2014) Good Psychiatric Practice: Code of Ethics (College Report CR186). Royal College of Psychiatrists.

Royal College of Psychiatrists (2016) Rethinking Risk to Others in Mental Health Services. Final Report of Scoping Group (College Report CR201). Royal College of Psychiatrists.

Ryan C, Nielssen 0, Paton M et al (2010) Clinical decisions in psychiatry should not be based on risk assessment. Australasian Psychiatry, 18: 398-403.

Shepherd G, Boardman J, Slade M (2008) Making Recovery a Reality. Sainsbury Centre for Mental Health.

Shepherd G, Boardman J, Burns M (2010) Implementing Recovery: A Methodology for Organisational Change. Sainsbury Centre for Mental Health.

Sykes M, Brabban A, Reilly $\mathrm{J}$ (2015) Balancing harms in support of recovery. Journal of Mental Health, 24: 140-4.

Szmukler G, Holloway F (2001) Mental Health Law: Discrimination or Protection? (Maudsley Discussion Paper No 10). King's College London.

Szmukler G, Rose N (2013) Risk assessment in mental health care: values and costs. Behavioral Sciences and the Law, 31: 125-40.

Young AT, Green CA, Estroff SE (2015) New endeavors, risk-taking, and personal growth in the recovery process: findings from the STARS study. Psychiatric Services, 59: 1430-6.
MCQ answers

$1 \mathrm{~b} \quad 2 \mathrm{~d} \quad 3$ e $\quad 4$ a $\quad 5 \mathrm{c}$ 
$\mathrm{MCOs}$

Select the single best option for each question stem

1 Therapeutic risk-taking:

a involves predicting which outcome is most likely

b involves patients making decisions regarding their own safety

c involves always prioritising autonomy

$d$ does not require risk management plans

$\mathrm{e}$ is best led by the professional.

2 Current risk assessments are dominated by:

a iatrogenic risks

b vulnerability of people with mental health problems

c risks of absconding d risks of harm to self and others

e harms associated with loss of freedom.

3 Involving patients in risk assessments can:

a lead to more successful predictions

$b$ increase the likelihood of relapse

c reinforce the potential for harm to self and others

$\mathrm{d}$ result in more adverse incidents

e broaden understanding of risk and include wider range of harms.

4 Therapeutic risk-taking may be inhibited by:

a a lack of clear organisational guidelines

b undertaking risk assessments

c engaging in dialogue with patients about risk $\mathrm{d}$ engaging in dialogue with carers about risk

e engaging in dialogue with the multidisciplinary team about risk.

5 Promoting therapeutic risk-taking in practice involves:

a increasing risk assessment documentation

b introducing mandatory clinical supervision

c developing shared spaces to tolerate uncertainty

$d$ auditing occurrences of therapeutic risk-taking

e removing risk management plans. 